\title{
A queda do céu: representação e mímesis em uma "arte índia"1
}

PEDRO ERNESTO FREITAS LIMA

Pedro Ernesto Freitas Lima é doutorando do Programa de Pós-Graduação em Artes Visuais da Universidade de Brasília (UnB), na linha de Teoria e História da Arte, pesquisa narrativas curatoriais de caráter identitário. Graduado em Desenho Industrial pela Universidade de Brasília e Mestre em Arte pelo PPG em Artes Visuais da mesma instituição. (<http://lattes.cnpq.br/5379538202080398>).

AFILIAÇÃO: Universidade de Brasília (UnB) Brasília DF, Brasil .

1 O presente trabalho foi realizado com apoio da Coordenação de Aperfeiçoamento de Pessoal de Nível Superior - Brasil (CAPES) - Código de Financiamento 001.

ouvirouver Uberlândia v. 15 n. 1 p. 126-141 jan. |jun. 2019 


\section{RESUMO}

Pelo menos desde 2010, Moacir dos Anjos tem realizado curadorias de exposições de artes visuais nas quais, partindo de motes literários, discute com produções artísticas a situação de determinados discursos subalternos sob uma perspectiva póscolonial. Entre elas, $A$ queda do céu, realizada no Paço das Artes em São Paulo no ano de 2015, parte da obra homônima escrita pelo yanomami Davi Kopenawa junto ao antropólogo francês Bruce Albert para tratar da "questão indígena" e reivindicar o reconhecimento de uma produção artística no Brasil comprometida em trazer essa questão para o campo do sensível como "arte índia". Pretendemos discutir aqui como a curadoria aciona procedimentos de representação e mímesis, recorrentes em muitas obras, de modo a construir seu argumento político a partir de diálogos com a obra de difícil classificação de Kopenawa e Albert.

\section{PALAVRAS-CHAVE}

"Arte índia", curadoria, representação, mímesis.

\section{ABSTRACT}

At least since 2010, Moacir dos Anjos has curated visual art exhibitions where, starting from literary motes, he discusses the situation of certain subaltern discourses from a postcolonial perspective. Among them, $A$ queda do céu, held in the Paço das Artes, São Paulo, in 2015, is part of a homonymous work written by the Yanomami David Kopenawa with the French anthropologist Bruce Albert to address the "indigenous question" and demand the recognition of an artistic production in Brazil committed to bringing this issue to the aesthetic field as "arte índia". We intend to discuss here how the curatorship triggers procedures of representation and mímesis, recurrent in many works, in order to construct his political argument from dialogues with the mentioned literary work.

\section{KEYWORDS}

"Arte índia", curatorship, representation, mímesis. 
Atuando como curador, crítico, pesquisador em artes visuais e gestor de museu, Moacir dos Anjos tem se interessado por uma produção artística que poderia ser associada às problemáticas denominações "periférica", "local", "regionalista" ou "subalterna". Partindo de um referencial pós-colonial, Anjos tem feito curadorias de exposições desde o final dos anos 1990 em que investiga relações identitárias a partir de critérios geográficos - como é o caso de seu interesse pelos "artistas nordestinos" - e sociais, como é o caso de suas curadorias mais recentes nas quais se interessa pela representação nas artes de grupos marginalizados aos quais são negados a cidadania por meio da supressão de direitos. Partindo da ideia de "literatura menor", elaborada por Gilles Deleuze e Félix Guattari para a obra de Franz Kafka, Anjos propõe falar, para esses casos, em uma "arte menor" (ANJOS, 2017, p. 155), ou seja, uma arte que

se vale do vasto repertório de conhecimentos artísticos produzidos em toda parte (inclusive os autóctones), gradualmente acessíveis a mais e mais gente, para, a partir de um ponto de vista singular, acolher parte deles, descartar outro tanto e articular tudo aquilo de que se apropriou de um modo que lhe é único. A arte menor adiciona, dessa maneira, inflexões e sotaques específicos para a chamada língua internacional da arte, aquela que [...] reproduz seus valores particulares e contingentes como se fossem consensuais e permanentes (ANJOS, 2017, p. 156-157).

Essa concepção minoritária é estendida à curadoria, sendo possível, portanto, falar em "curadoria menor", estratégia que coloca em dúvida formas hegemônicas de funcionamento do mundo corrente - e aqui podemos considerar os mais diversos âmbitos: social, político, artístico, entre outros - e de suas certezas (ANJOS, 2017, p. 158).

Podemos considerar a exposição A queda do céu (2015), montada inicialmente no Paço das Artes, em São Paulo, filiada a uma série de curadorias nas quais Moacir dos Anjos parte de um mote literário para apresentar uma seleção de obras de artes visuais que representam sujeitos marginalizados ${ }^{2}$. Tendo como referência a obra do xamã yanomami Davi Kopenawa escrita conjuntamente com o antropólogo francês Bruce Albert, Anjos discute a representação indígena na produção contemporânea de artistas brasileiros, estrangeiros e indígenas. Discutiremos como essa exposição debate a "questão indígena", isto é, "uma história longa e continuada de roubo, agressão e silenciamento, protagonizada tanto por agentes particulares como por representantes do Estado" (ANJOS, 2016b, on-line), a partir dos procedimentos artísticos da mímesis e da Representação, procedimentos esses que, tendo como objetivo a representação do semelhante, tem como inerente à sua prática a criação/produção e a diferença. Tensão essa que podemos considerar presente tanto na curadoria de Anjos em questão quanto na "contra-antropologia" realizada por Kopenawa e Albert.

\footnotetext{
${ }^{2}$ As duas outras curadorias com essa proposta são Há sempre um copo de mar para um homem navegar (2010, 29ạ Bienal de São Paulo), na qual, ao lado de Agnaldo Farias, Anjos discute aproximações entre arte e política; e Cães sem plumas (2014, Museu de Arte Moderna Aloisio Magalhães, Recife), que debateu a presença de despossuídos e marginalizados na arte.
} 
Para isso, inicialmente apresentaremos a exposição, nos detendo sobre algumas obras em particular, especialmente sobre Brasil nativo / Brasil alienígena (1977) de Anna Bella Geiger. Tendo em vista a proposta curatorial em questão, discutiremos como a curadoria de Anjos aciona na obra de Geiger o problema da Representação e da mímesis de modo que o relato de Kopenawa e a opção decolonial passam a ser possibilidades de abordagem da obra Brasil nativo / Brasil alienígena. Finalmente, partindo de uma análise de como essa exposição representa a alteridade em termos de opacidade e transparência, debateremos a possibilidade de aproximação dessa curadoria de uma ação decolonial.

\section{Um olhar sobre a exposição}

Se continuarem se mostrando tão hostis para conosco, os brancos vão acabar matando o pouco que resta de nossos xamãs mais antigos. [...] esses homens que sabem se tornar espíritos desde um tempo remoto têm um valor muito alto. Bebem o pó de yãkoana continuamente, para nos curar e proteger. Repelem os espíritos maléficos, impedem a floresta de se desfazer e reforçam o céu quando ameaça desabar. [...] se desaparecerem todos [os xamãs], a terra e o céu vão despencar no caos. É por isso que eu gostaria que os brancos escutassem nossas palavras e pudessem sonhar eles mesmos com tudo isso, porque, se os cantos dos xamãs deixarem de ser ouvidos na floresta, eles não serão mais poupados do que nós. (KOPENAWA; ALBERT, 2015, p. 491).

Esse é um dos trechos no qual o xamã yanomami Davi Kopenawa alerta para o que acontecerá caso o homem branco, visando atender sua crescente e "insaciável" demanda por recursos naturais, prossiga com o seu comportamento hostil em relação ao meio ambiente. Tal anseio por recursos naturais visa o financiamento de um modelo de progresso predatório, constituinte de um dos pilares da nossa modernidade ocidental. Essa advertência é tomada por Moacir dos Anjos como mote para discutir a condição das vozes indígenas a partir das artes visuais na exposição $A$ queda do céu.

O livro de Kopenawa, escrito juntamente com o antropólogo francês Bruce Albert, apresenta a cosmogonia fundante da crença dos yanomami e narra a trajetória do xamã, o qual atua como líder e militante da "questão indígena". Depois que sua boca "perdeu a vergonha" de falar a língua dos brancos, a partir de 1983, Kopenawa passou regularmente a "fazer chegar aos brancos os pensamentos dos habitantes da floresta e lhes falar com firmeza, inclusive em suas cidades" (KOPENAWA; ALBERT, 2015, p. 383) sobre as atividades ameaçadoras - não só para povos indígenas, mas também para os próprios brancos - como a mineração, o desmatamento, a construção de barragens e a introdução, muitas vezes voluntária, de doenças que devastam populações indígenas. Segundo Anjos, essas ações brutais e predatórias visam, em última instância, "a apropriação patrimonial das terras que os povos ameríndios habitam, levando-os a uma situação de despossessão absoluta que os priva do território físico e simbólico ao qual pertencem" (ANJOS, 2016a, p. 11). 
Segundo Anjos, essa curadoria tinha como objetivo

aproximar e articular trabalhos artísticos que prenunciam, evidenciam e combatem a progressiva despossessão sofrida por populações indígenas iniciada em seu contato involuntário com o colonizador branco: aquele que lhes quis e ainda quer subtrair a sua condição de humanos, e que não suporta o convívio com a diferença. (ANJOS, 2016a, p. 14).

A tomada de posição pelo curador é evidente quando esse afirma que entre seus objetivos está reunir e, portanto, amplificar vozes que "evidenciam" e "combatem" o processo contínuo de degradação infligido aos povos indígenas. Entre os artistas presentes em $A$ queda do céu estão alguns nascidos ou residentes no Brasil, como Anna Bella Geiger, Cildo Meireles, Claudia Andujar, Leonilson, Maria Thereza Alves, Matheus Rocha Pitta, Miguel Rio Branco, Paulo Nazareth e Vicente Carelli; e outros estrangeiros como Harun Farocki, Jimmie Durham, Paz Errázuriz e Regina José Galindo; além de indígenas como Orlando Nakeuxima Manihipi-ther e Ailton Krenak. Ao escolher artistas de diferentes origens geográficas e étnicas, Anjos enfatiza a mensagem de Kopenawa de que o céu que ameaça desabar é uma unidade, e por isso não reconhece fronteiras e limites de territórios, afetando brancos e indígenas sem distinção. Vejamos algumas obras presentes na mostra.

Claudia Andujar se tornou referência de artista ativista desde quando começou a fotografar os yanomami em 1971 para a revista Realidade. Sua fotografia explora tanto uma dimensão lírica das práticas indígenas - como na série Yanomami (1971-1977), na qual Andujar está interessada nos momentos de transe de xamãs e no espaço insólito criado no interior das ocas devido à iluminação peculiar proveniente de frestas na cobertura de palha dessas moradias - como também realiza denúncia social, caso da série Marcados (1981-1983) (Figura 1), presente em A queda do céu. A série foi realizada em um momento no qual indígenas eram vacinados para serem protegidos de uma epidemia provocada pela aproximação dos brancos devido a construção da Rodovia Perimetral Norte. Identificando os fotografados com números, à maneira das imagens de condenados pela realização de algum crime, Andujar denuncia a situação precária e limiar de vida daqueles yanomamis.

Outras obras fotográficas estiveram presentes na exposição, como Kawésqar, os nômades do mar (1996) (Figura 2), trabalho da chilena Paz Errázuriz, que representa os últimos membros da etnia Kawésqar que ainda habitam a região austral do Chile, e a série Brasil (2013) (Figura 3), na qual Matheus Rocha Pitta, utilizando um procedimento que poderíamos considerar como metonímico, fotografa a icônica terra vermelha de Brasília. A observação atenta das imagens de Pitta revela pedaços de carne entremeados à terra (PRÊMIO PIPA, 2014, on-line). Considerando a proposta curatorial, a carne camuflada torna-se sugestão de violência, nos remetendo, por exemplo, aos confrontos por disputas de terra, nos quais são recorrentes os assassinatos de indígenas. 


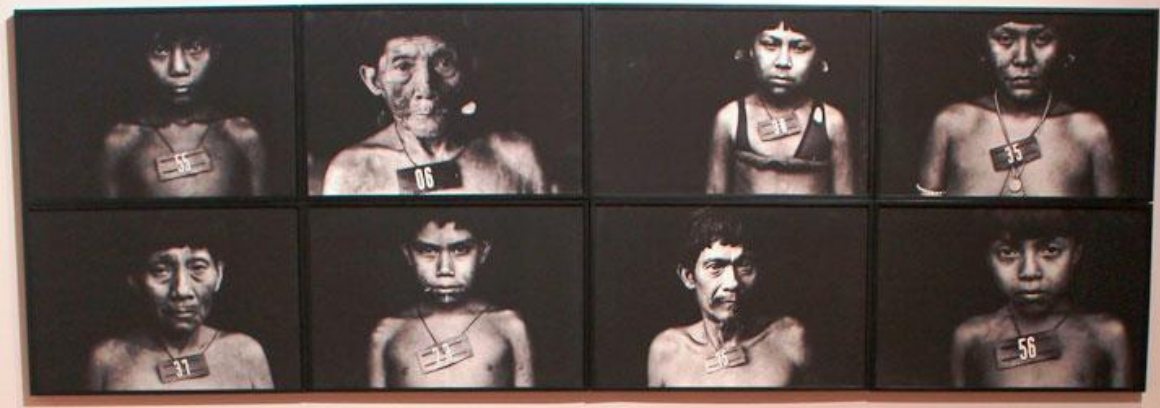

Figura 1. Claudia Andujar, Marcados, 1981-1983, fotografia. Vista da exposição A queda do céu, Paço das Artes, São Paulo, 2015.

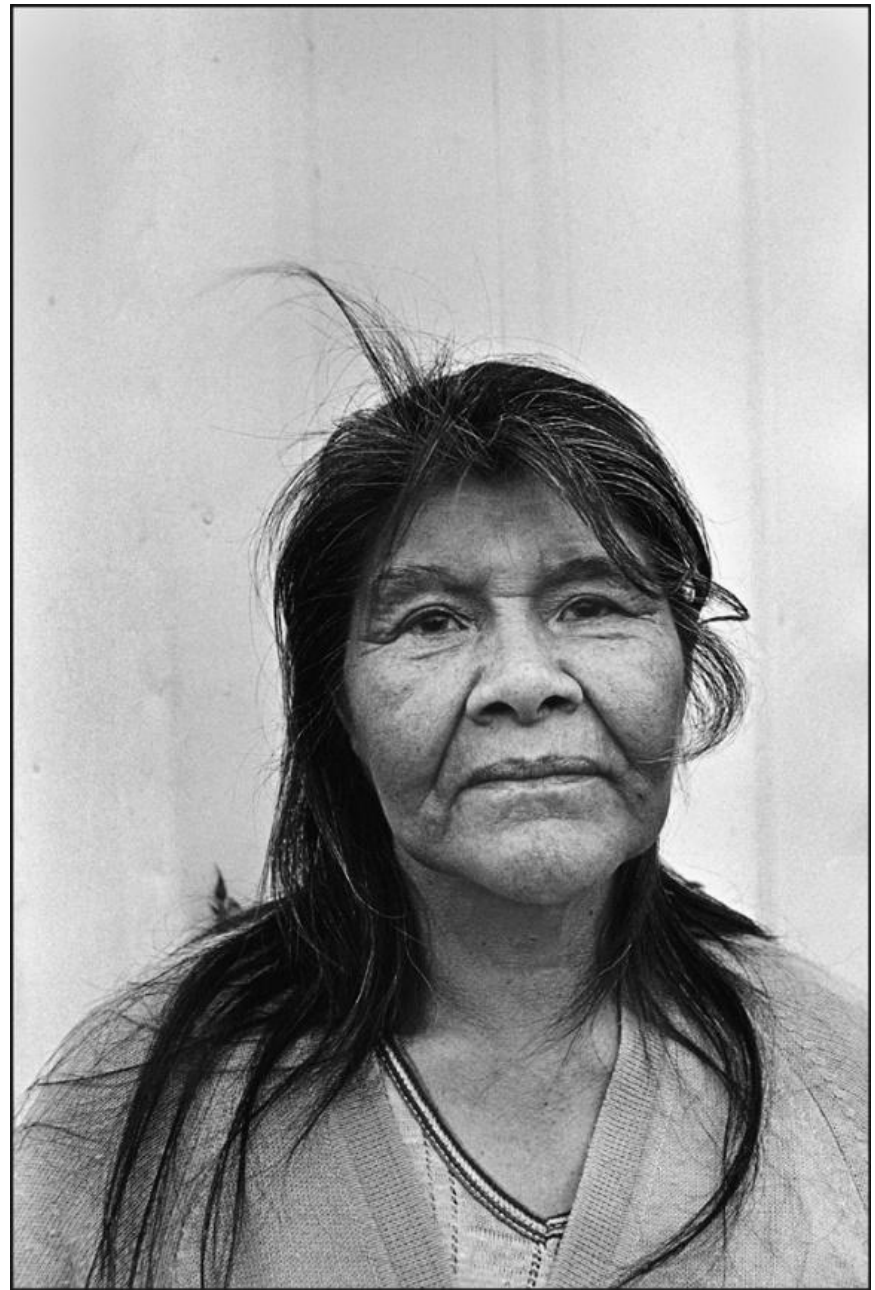

Figura 2. Paz Errázuriz, Kawésqar, os nômades do mar (1996), fotografia. 

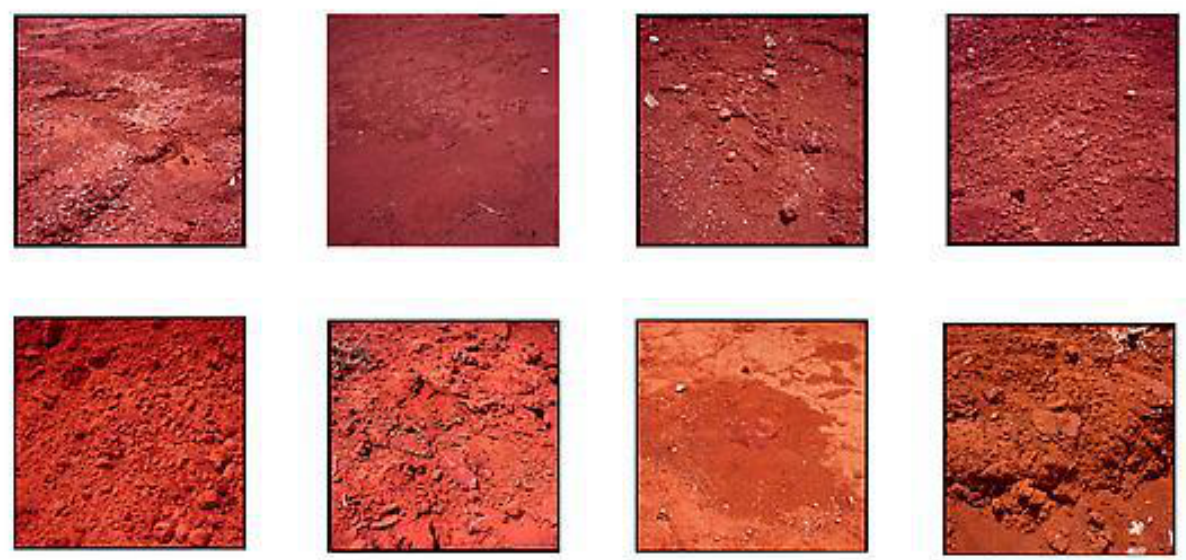

Figura 3. Matheus Rocha Pitta, Brasil, 2013, fotografia.

Tierra (2013) (Figura 4), da guatemalteca Regina José Galindo, também comenta a investida contra terras indígenas, fazendo referência ao procedimento da terra arrasada usada pelo governo militar da Guatemala que, após chegar ao poder por meio do golpe de 1954, passou a perseguir, com apoio da oligarquia agrária local, povos indígenas, os quais eram considerados inimigos do regime. A performance de Galindo faz referência às fossas escavadas para sepultar corpos de indígenas mortos nesse enfrentamento ${ }^{3}$.

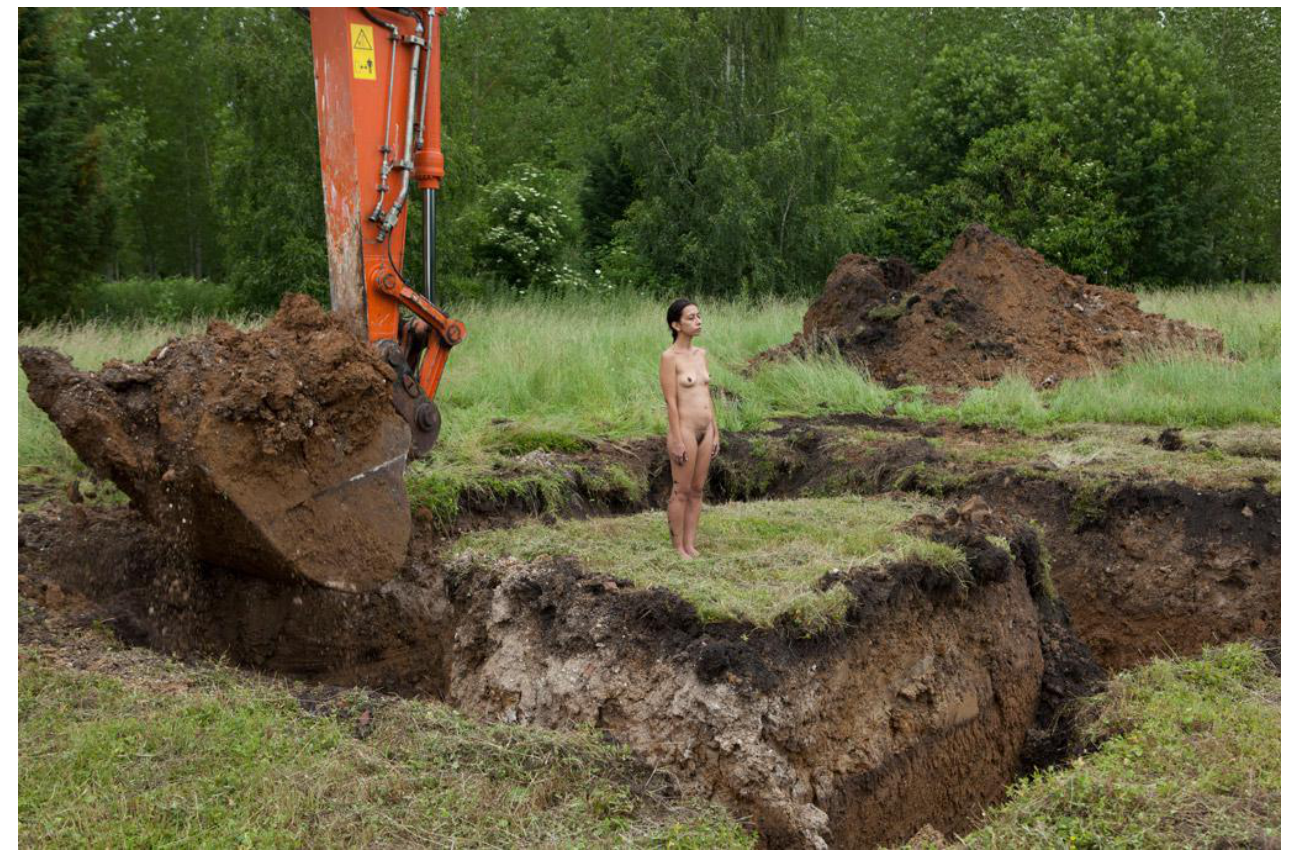

Figura 4. Regina José Galindo. Tierra, 2013, performance, vídeo.

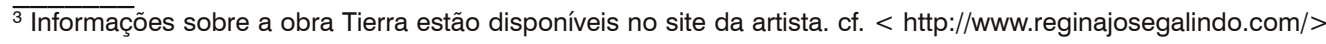
Acesso: 20 nov. 2017.
}

ouvirouver Uberlândia v. 15 n. 1 p. 126-141 jan. |jun. 2019 
Outro artista presente na exposição é Cildo Meireles. A partir dos anos 1960 o artista integrou uma geração que partiu da aproximação entre arte e sociedade para comentar e criticar, por meio de trabalhos pretensamente políticos, as dimensões social, cultural e política do país que, naquele momento, estava subjugado ao violento e autoritário regime militar. Duas obras de Meireles estão expostas em $A$ queda do céu. Sal sem carne (1976-2006) (Figura 5), uma instalação sonora e fotográfica produzida a partir de um áudio gravado nos anos 1970 que, segundo o próprio Meireles, tinha como objetivo produzir uma "radionovela sobre a situação do gueto em geral" (GRANDO, 2016b, on-line). A obra é resultado da sobreposição de registros de entrevistas com índios caiapós, os quais viviam naquele momento em situação marginal em Goiás, a vozes de homens brancos em meio a festas religiosas populares de matriz cristã realizadas na mesma região. Os ruídos resultantes de difícil entendimento compõe o espaço junto com cento e quarenta e quatro monóculos suspensos por fios, os quais permitem ver imagens de índios Krahôs e de habitantes de Trindade, cidade próxima ao local de onde teriam partido ordens de fazendeiros locais para o massacre dos mencionados índios (idem, ibidem).

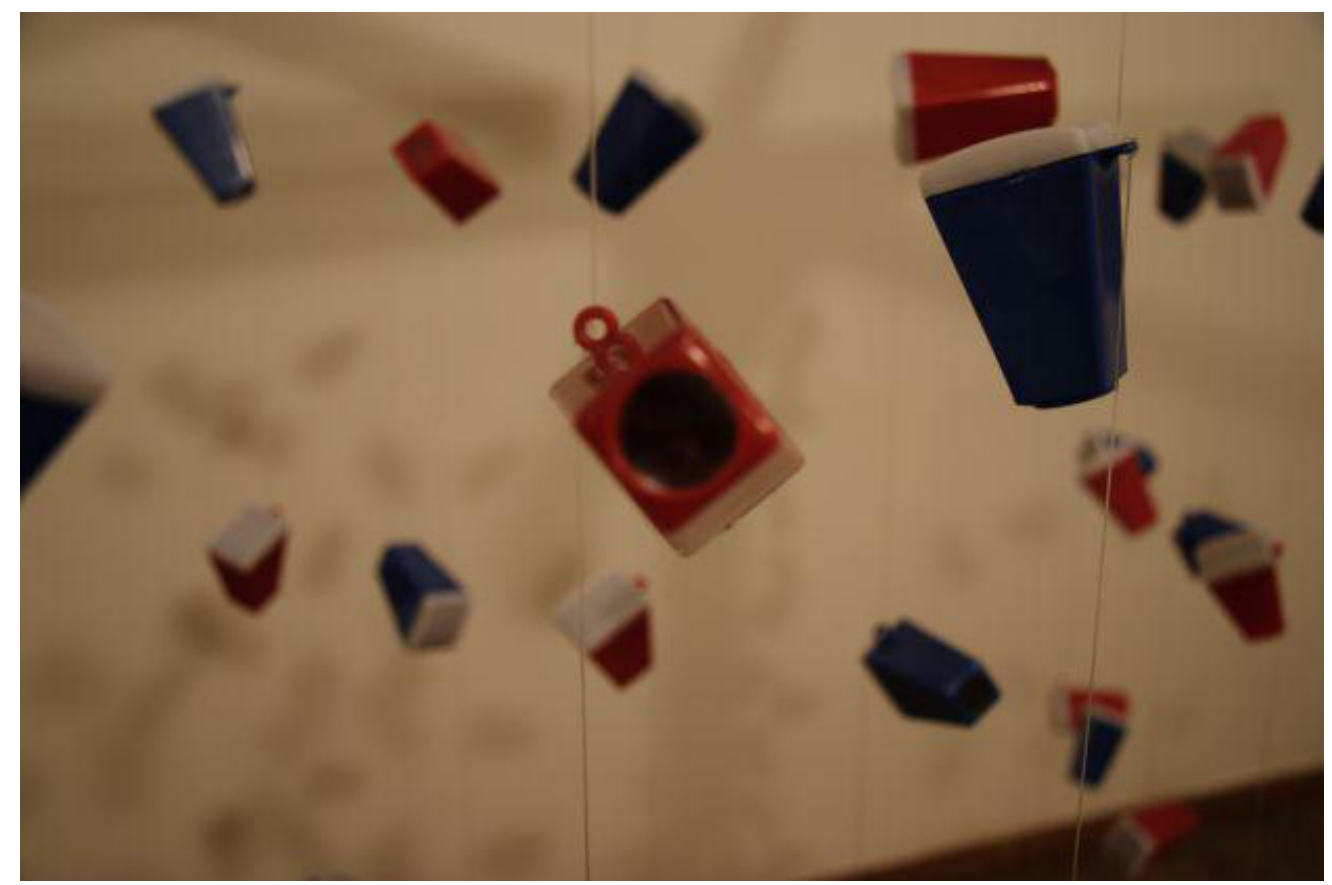

Figura 5. Cildo Meireles, Sal sem carne, 1976-2006, instalação. Vista da exposição A queda do céu, Paço das Artes, São Paulo, 2015.

A outra obra de Meireles exposta é Zero real (2013) (Figura 6), na qual o artista elege as imagens de um indígena e de um interno de manicômio para representar, na forma de efígies, o valor quantitativo zero. Zero real faz parte da conhecida série na qual o artista insere, em determinados objetos familiares, elementos desviantes em relação àquilo que é considerado padrão. Ao (re)inserir em seus circuitos de origem os objetos modificados, Meireles ativa e subverte os próprios circuitos de circulação de símbolos e valores. 

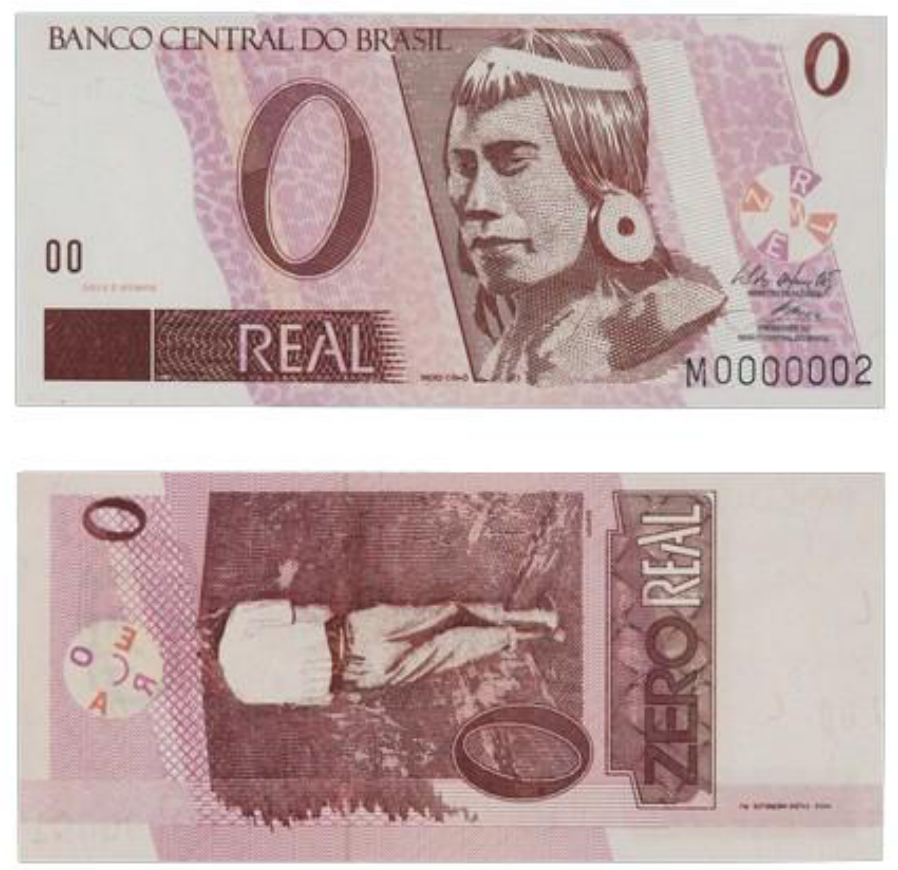

Figura 6. Cildo Meireles, Zero real, 2013.

Darei destaque aqui à série Brasil nativo / Brasil alienígena (1977) (Figura 7) de Anna Bella Geiger. Tomando como referência fotografias de povos indígenas realizando atividades cotidianas e que foram veiculadas como cartões postais pela editora Bloch nos anos 1970, a artista foi registrada pelo fotógrafo Luiz Carlos Velho encenando as mesmas situações ilustradas nos cartões. Os postais constroem imagens de indígenas enquanto seres idiossincráticos, habitantes de ambientes idílicos, construção próxima daquela consagrada pelo nosso modernismo dos anos 1920 , na qual o indígena costumava ser representado de modo hierático, como indivíduo integral e coerente do ponto de vista identitário e social, à margem de tensões, como na obra de Vicente do Rego Monteiro (CATTANI, 2011, p. 52).

Para Tadeu Chiarelli, a artista parece empreender uma "busca de identificação nostálgica com o elemento nativo brasileiro" que, na realidade, não passa de um procedimento irônico para que a artista possa falar de si mesma (CHIARELLI, 2002, p. 116). A aproximação provocativa e desconcertante das duas sequências de imagens resulta em um mero pastiche diante da tentativa de representação e identificação com o outro, nos sugerindo a própria impossibilidade dessa identificação (idem, ibidem). A assimetria entre os postais e as imagens de Geiger enfatiza a diferença entre seus protagonistas, o que nos evidencia problemas relacionados às categorias artísticas da mímesis e da Representação, questões seculares fundamentais da História da Arte e que foram centrais no debate artístico até pelo menos a produção moderna das últimas décadas do século XIX.

Segundo Luiz Costa Lima (2013, p. 102), a mímesis teria sido a primeira grande teoria ocidental sobre as artes. Gestada na Grécia antiga, foi discutida no livro X da República de Platão enquanto prática que resultava em imitações de cará- 
ter negativo uma vez que se afastavam das Ideias, do justo e do bom. Diferentemente da ideia de Leonardo da Vinci e de Albrecht Dürer do painel de vidro transparente interposto entre o referente e a mão do pintor, o qual garantiria uma reprodução do modelo em seu esplendor (HUCHET, 2012, p. 221), a mímesis não estabelece uma relação de transparência total entre referente e representado. Seu caráter de imitatio - termo consagrado no latim por Horácio - é sintetizado por Lima da seguinte forma: "na arte, a mímesis opera pela produção de diferença, cumprida a partir de um horizonte de semelhança." (LIMA, 2013, p. 116, grifo do autor). Diferença e semelhança estariam, nesse caso, em harmonia, em um acordo tenso e dinâmico.

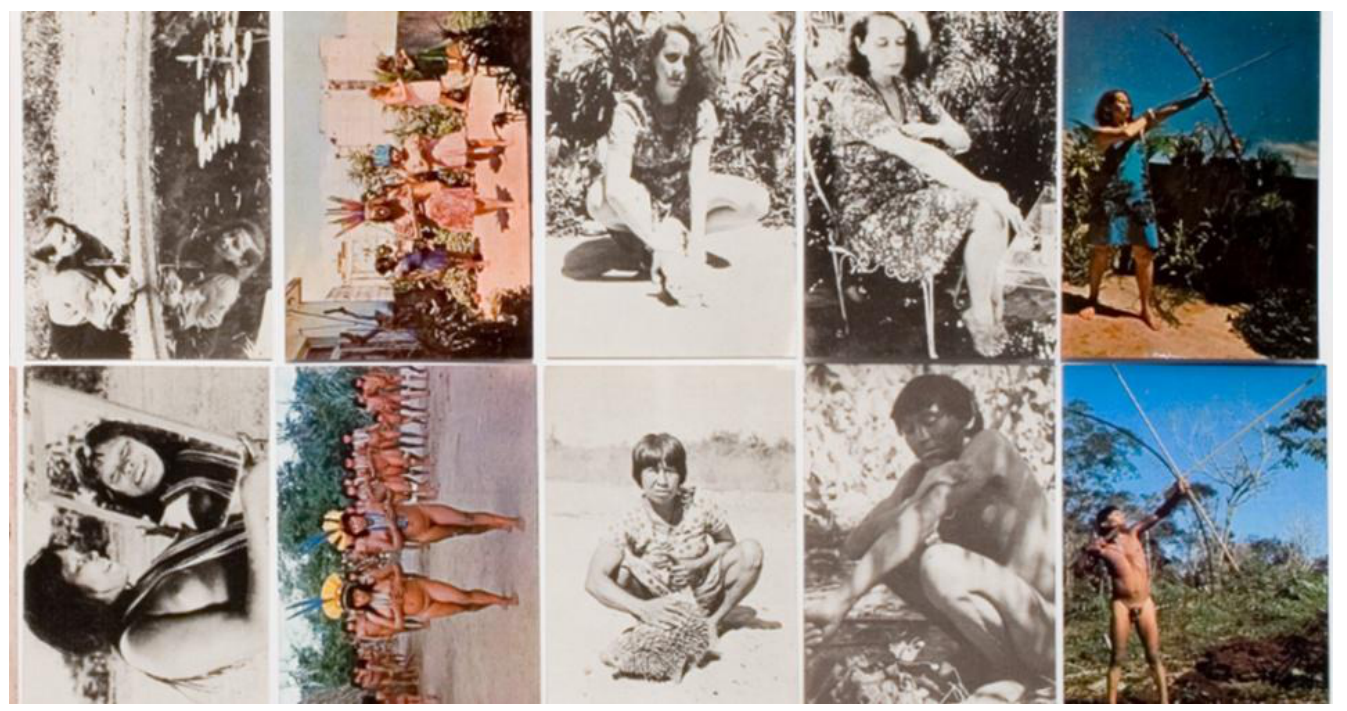

Figura 7. Anna Bella Geiger, Brasil nativo / Brasil alienígena, 1977, fotografia.

Stéphane Huchet, em seu texto Do ver ao mostrar, Representação e Corpus da arte também afirma a perspectiva de que "toda imagem é deveras invenção e que a Representação [...] é também um domínio produtivo, e não apenas 'reprodutivo'” (HUCHET, 2012, p. 222-223). O autor demonstra que no século XVI, Giorgio Vasari, ao teorizar a imitação da natureza, já havia introduzido a noção de invenção como uma "faculdade produtiva de natureza subjetiva" (idem, ibidem, p. 228) dentro do contexto do preceito do Natura vincere, isto é, a arte como superação da natureza já que "torna visível o que a imediatidade do sensível recobre" (PAYOT, 1997, p. 79 apud HUCHET, 2012, p. 229). A arti del disegno seria uma unidade de três etapas principais: a "extração", isto é, a recepção do sensível; a formação de um concetto (desenho interior, cosa mentale); e a expressão ou declaração (dichiarazione) desse concetto na forma sensível de uma obra (idem, ibidem apud idem, ibidem, p. 229230).

Nos séculos seguintes, a discussão sobre arte a partir de sua relação com a natureza e sua capacidade de representá-la continuou relevante, ainda que em termos diferentes. O século XVIII iluminista vinculou e condicionou o ver ao conhecimento, vinculação essa desfeita no século XIX, cujo interesse estava em alcançar 
uma pretensa inocência da percepção, uma "naturalidade" de cunho primitivista. O que é percebido nessas discussões é a disputa entre modelos culturais de "interpretação do real e da função perceptiva" (HUCHET, 2012, p. 232). A partir desse retrospecto, Huchet defende que a arte "não nasce da natureza, mas de certa ideia dela, e essa ideia já pertence inteiramente ao domínio da arte. A arte [portanto] nasce da arte." (idem, ibidem). Desse modo, toda arte "significa a escolha manifesta de um recorte específico - estratégico - da/na realidade visual, certo tipo de gerenciamento das aparências" (idem, ibidem, p. 233), constatação que leva Huchet a defender a presença da Representação - enquanto categoria artística - na produção moderna e contemporânea, inclusive quando se trata de produções não figurativas.

\begin{abstract}
Hoje, portanto, ainda se representa? Sim, porque ainda se encena, teatraliza-se, alegoriza-se, apresenta-se, expõe-se, isto é, recorre-se por essência ao exercício de produção de aparências significativas, porque geridas dentro de um sistema (ou de sistemas) que levam as poéticas visuais a inventar sequências críticas e a criar diferenças com os recursos dos signos. [...] Aliás, as recorrentes estéticas do corpo são, hoje, uma semiosis perfeita da indissociabilidade orgânica e simbólica da Representação intelectiva e da afirmação icônica crua. [...] a forte presença nela [na arte contemporânea] de um estrato representativo ajuda a entender que a função representacional não é exclusiva das épocas de arte ilusionista. (HUCHET, 2012, p. 253-254).
\end{abstract}

A obra de Anna Bella Geiger, ao pretender mimetizar o outro construído como idílico, explora a opacidade e a dimensão criadora da Representação e da mímesis. Há diferenças entre as fotografias da artista e as imagens dos postais, como a não adesão ao nu e à posição acocorada. Alternativamente a essas características, Geiger é retratada, nas imagens correspondentes, vestida e sentada em uma cadeira. Evidentemente, ainda temos que considerar suas diferenças fenotípicas, que nos levam a reconhecê-la como mulher, branca, provavelmente de classe média. Ainda, o título da obra enfatiza a diferença, por meio da oposição, dos termos nativo e alienígena e de seu contraste semântico presente na dualidade autenticidade e estrangeiridade / falsidade.

Diante do acionamento da relação entre opacidade e transparência na obra de Geiger, cabe ainda discutirmos como essa questão reverbera na exposição como um todo, tendo em vista sua proposta política.

\title{
2. Uma aproximação tensa
}

Moacir dos Anjos afirma seu incômodo com o fato de que a "questão indígena" tenha sido tão pouco investigada no país pela arte, pelas instituições e por seus profissionais, entre eles os curadores. Anjos faz então uma analogia entre as obras escolhidas para a exposição e a situação de subalternidade dos povos indígenas, propondo compreender essa produção artística filiada àquilo que nomeia como "arte índia". Essas obras, segundo o curador, por serem "vozes minoritárias em meio a um eloquente silêncio que as cerca, é provável que o ruído que produ- 
zem não consiga se transformar, por seus próprios meios, em discurso articulado e público." (ANJOS, 2016b, on-line).

Essa tentativa de articular e amplificar vozes minoritárias nos leva a considerar que $A$ queda do céu complexifica a noção geralmente aceita de curadoria enquanto construção diacrônica da história da arte ou como espetacularização e rendição ao status quo do capitalismo, como propõe Rosalind Krauss ao se deparar com o encontro entre museu e arte contemporânea a partir dos anos 1960 (apud OSORIO, 2015, p. 73). Naquele momento falava-se em uma "virada curatorial", expressão utilizada para designar a centralidade do curador como propositor de narrativas alternativas em um contexto no qual as grandes narrativas passaram a ser questionadas. Indo além da concepção de Krauss, Luiz Camillo Osorio entende que a virada curatorial remete

à experimentalidade inerente à quebra das grandes narrativas progressistas ou enciclopédicas, e à procura constante por outras narrativas heterogêneas que ampliem nossas possibilidades de, através de exposições-ensaios, com a "mão forte", mas não arbitrária da curadoria, imaginar outros passados esquecidos e inventar futuros inimagináveis no presente. No mínimo, essa virada curatorial visa provocar experiências que resistam às expectativas impostas pelos afetos e discursos hegemônicos. (OSORIO, 2015, p. 79).

Voltando à obra de Kopenawa e Albert, para Eduardo Viveiros de Castro (2015, p. 24), A queda do céu é "a primeira tentativa sistemática de 'antropologia simétrica', ou 'contra-antropologia', do Antropoceno, a época geológica atual”. Com essa afirmação, Castro quer ressaltar que o relato oferece "uma explicação do mundo segundo outra cosmologia e uma caracterização dos Brancos segundo outra antropologia" motivada por uma curiosidade recíproca, originária tanto do antropólogo escritor quanto do xamã narrador. Essa preocupação em dar visibilidade a uma outra narrativa, a uma outra cosmologia e a outros modelos possíveis de organização social é uma questão comum à obra literária, à curadoria de Anjos em questão - considerando aqui também o que Osorio entende como a função do curador - e ao que Walter Mignolo chama de opção decolonial.

O pensamento e a ação decolonial questionam padrões coloniais de poder hegemônicos no Ocidente em domínios como a economia, o poder, o gênero, a sexualidade e a subjetividade, os quais são permeados pela retórica moderna do desenvolvimento, do progresso, da modernização, da salvação e da democracia (MIGNOLO, 2011, p. 14), valores fundamentais da epistemologia ocidental. Para Mignolo, a epistemologia indigenista, particularmente a noção de "comunal", e a colocação entre parênteses de conceitos como os de "verdade" e "objetividade" seriam a base do questionamento do "padrão colonial de poder", o que, consequentemente, ensejaria possibilidades decoloniais (idem, ibidem, p. 9-10; 52).

Dito isso, poderíamos afirmar que essa exposição pode ser entendida como uma proposta de fundo decolonial, na qual está em questão a visibilidade e a vocalização de sujeitos subalternizados - ainda que esse termo pertença ao vocabulário pós-colonial, ramo dos estudos culturais que, para Mignolo, ainda está assentada 
em uma epistemologia eurocêntrica (BALLESTRIN, 2013, p. 95) - e a necessidade de um posicionamento questionador do pensamento hegemônico, universalista e eurocêntrico fundador da modernidade, sem contudo - e isso é fundamental enfatizar - perder de vista valores intrínsecos à arte como a opacidade, a ambiguidade e a polissemia. Assim como a proposta da obra de Kopenawa e Albert de realização de uma "antropologia simétrica" ou uma "contra-antropologia", as obras selecionadas por Anjos sugerem ao espectador a necessidade de uma contra-narrativa para pensarmos a "questão indígena". No entanto, quando notamos a presença reduzida de artistas indígenas nessa exposição, passamos a questionar sua suposta prática decolonial. Eduardo Viveiros de Castro faz a seguinte observação sobre narrativas etnográficas:

Recusar aos índios uma interlocução estética e filosófica radicalmente 'horizontal' com nossa sociedade, relegando-os ao papel de objetos de um assistencialismo terceirizado, de clientes de um ativismo branco esclarecido, ou de vítimas de um denuncismo desesperado, é recusar a eles sua contemporaneidade absoluta. (CASTRO, 2015, p. 34).

Anjos expõe desenhos do xamã Orlando Nakeuxima Manihipi-ther e um vídeo do discurso do líder político Ailton Krenak na Assembleia Nacional Constituinte em 1987. Há ainda um vídeo de Paulo Nazareth (Aprender a rezar Guarani Kaiowá para o mundo não acabar [2012]), sem imagens, reproduzindo apenas o registro sonoro de ações ritualísticas de integrantes da tribo Guarani Kaiowá. Nessa exposição, vozes indígenas em primeira pessoa são minoritárias, o que nos evidencia o interesse da curadoria pela exploração da diferença e da opacidade inerentes à mímesis e à Representação enquanto procedimentos poéticos. Essa proposta curatorial reverbera questão semelhante ao que discutimos sobre Brasil nativo / Brasil alienígena: evidencia, ao falar sobre o outro, sua distância e diferença em relação a ele.

Caso a opção da curadoria fosse por uma maior presença de artistas indígenas, a exposição correria o risco de ser revestida pelos vernizes da autenticidade e da transparência, o que talvez a reduzisse a um evento de arte política. Contrariamente, percebemos que o interesse de Anjos está em realizar um evento de arte e política ou de "política da arte". Ao se desviar da ingenuidade e do voluntarismo, a "política da arte"

se expressa no poder que a criação artística tem de embaralhar as coordenadas sensoriais com que usualmente se experimenta o mundo, abrindo fissuras nas convenções e nos consensos que organizam tanto a vida pública como a íntima. E é por ser capaz de desconcertar os sentidos, e de subjetivar esse desconcerto, que a arte pode, pelos próprios meios, reconfigurar os temas e as atitudes que se inscrevem nos espaços comuns de existência. É isso que assegura o lugar único que a arte ocupa na organização da vida e afirma sua capacidade de esclarecer e de reinventar as formas em que o mundo se estrutura (ANJOS, 2012. p. 13). 
O também curador Gabriel Bogossian (2017, on-line) aponta lacunas no trabalho de Anjos, entre elas a ausência de "anteparos discursivos" - críticos, etnográficos ou históricos - para os desenhos yanomami exibidos, e de uma autocrítica do campo da arte que coloque em dúvida os próprios limites do campo. Entendemos que a crítica de Bogossian expressa um desejo pela aproximação e pela tradução da alteridade. Podemos evocar novamente a dificuldade de aproximação do outro percebida na obra de Anna Bella Geiger para afirmar que o reconhecimento dessa tensão, e não a tentativa de resolvê-la, é um dos méritos da exposição $A$ queda do céu. Explorar no âmbito institucionalizado da arte os limites de interlocução entre vozes minoritárias, geralmente desarticuladas, consciente da limitação inerente a esses processos pretensamente representativos, impede que a exposição seja reduzida a um evento panfletário no qual a polissemia das obras estaria comprometida.

\section{REFERÊNCIAS}

BANDUJAR, Claudia Andujar. Marcados, fotografia, 1981-1983, vista da exposição A queda do céu, Paço das Artes, São Paulo, 2015. Fonte: ANJOS, Moacir. A queda do céu. Folheto de exposição. São Paulo, SESC Rio Preto, 2016.

https://doi.org/10.4000/artelogie.882

ANJOS, Moacir dos. "Arte menor, gambiarra e sotaque". In: FIALHO, Ana Letícia et al. Depois do muro. Recife: Fundação Joaquim Nabuco, Editora Massangana, 2010. p.111-128.

https://doi.org/10.1017/s0963926800380282

"Por uma política da arte". In: Carlos Vergara Liberdade. Impresso de exposição. São Paulo: Memorial da Resistência de São Paulo, 2012.

https://doi.org/10.1590/s0102-88392004000400004

"A queda do céu". In: A queda do céu. Folheto de exposição. São Paulo, SESC Rio Preto, $2016 a$.

. "Arte índia". In: Revista Zum/colunistas, São Paulo, 9 jun. 2016b. Disponível em:

<https://revistazum.com.br/colunistas/arte-india/> Acesso: 15 out. 2017.

"Por uma curadoria menor". In: ANJOS, Moacir dos. Contraditório: arte, globalização e

pertencimento. Rio de Janeiro: Cobogó, 2017. p. 155-168.

BALLESTRIN, Luciana. "América Latina e o giro decolonial”. In: Revista Brasileira de Ciência Política, n.11, Brasília, mai-ago 2013, p.89-117.

https://doi.org/10.1590/s0103-33522013000200004

BOGOSSIAN, Gabriel. "Um museu ausente: curadoria contemporânea e ativismo indigenista". In: Artelogie, n. 10, 2017. Disponível em: <http://artelogie.revues.org/882> Acesso: 17 out. 2017.

https://doi.org/10.4000/artelogie.882

ouvirouver Uberlândia v. 15 n. 1 p. 126-141 jan.|jun. 2019 
CATTANI, Icleia. Arte Moderna no Brasil. Belo Horizonte: C/Arte, 2011.

CASTRO, Eduardo Viveiros. "Prefácio: O recado da mata". In: KOPENAWA, Davi; ALBERT, Bruce. A queda do céu. São Paulo: Companhia das Letras, 2015. p. 11-41

CHIARELLI, Tadeu. "A fotografia contaminada". In: CHIARELLI, Tadeu. Arte internacional brasileira. São Paulo: Lemos-Editorial, 2002. p.115-120.

ERRÁZURIZ, Paz. Kawésqar, os nômades do mar, fotografia, 1996. Fonte: ANJOS, Moacir. A queda do céu. Folheto de exposição. São Paulo, SESC Rio Preto, 2016.

GALINDO, Regina José. Tierra, performance, vídeo, 2013. Fonte: fotografia disponível em < http://www.reginajosegalindo.com/tierra/> Acesso: 30 out. 2017.

GEIGER, Anna Bella. Brasil nativo / Brasil alienígena, fotografia, 1977. Fonte: fotografia disponível em <http://mam.org.br/acervo/2006-003-000-geiger-anna-bella/> Acesso: 30 out. 2017.

https://doi.org/10.1093/oao/9781884446054.013.2000000107

GRANDO, Ângela. "Sal sem carne - para uma estética do gueto". In: Artelogie, n. 8, 2016. Disponível em: $<$ https://artelogie.revues.org/496> Acesso em out. 2017.

https://doi.org/10.4000/artelogie.496

HUCHET, Stéphane. "Do ver ao mostrar, Representação e Corpus da arte”. In: HUCHET, Stéphane (org.). Fragmentos de uma teoria da arte. São Paulo: Editora da Universidade de São Paulo, 2012. https://doi.org/10.11606/d.93.2016.tde-16032016-173305

KOPENAWA, Davi; ALBERT, Bruce. A queda do céu. São Paulo: Companhia das Letras, 2015.

LIMA, Luiz Costa. Frestas: a teorização de um país periférico. Rio de Janeiro: Contraponto: Ed. PUCRio, 2013.

Matheus Rocha Pitta e Opavivará participam da Bienal de Taipei. In: Prêmio Pipa, 24 out. 2014. Disponível em: <http://www.premiopipa.com/2014/10/matheus-rocha-pitta-e-opavivara-participam-da-bienal-de-taipei/> Acessado em: out 2017.

https://doi.org/10.1093/oao/9781884446054.013.2000000028

MEIRELES, Cildo. Sal sem carne, 1976-2006, instalação. Vista da exposição A queda do céu, Paço das Artes, São Paulo, 2015. Fonte: fotografia disponível em <https://artelogie.revues.org/496> Acesso: 30 out. 2017.

MEIRELES, Cildo. Zero real, 2013. Fonte: ANJOS, Moacir. A queda do céu. Folheto de exposição. São Paulo, SESC Rio Preto, 2016.

MIGNOLO, Walter. The diker side of western modernity. Durham e Londres: Duke University Press, 2011.

OSORIO, Luiz Camillo. "Virada curatorial: o pôr-em-obra da exposição como poética relacional”. In: Re-

ouvirouver Uberlândia v. 15 n. 1 p. 126-141 jan.|jun. 2019 
vista Poiésis, n. 26, dez. 2015. p. 65-80. p. 73.

https://doi.org/10.22409/poiesis.1626.65-80

PITTA, Matheus Rocha. Brasil, fotografia, 2013. Fonte: fotografia disponível em <http://www.sprovie-

ri.com/artists/matheus-rocha-pitta/> Acesso: 30 out. 2017.

https://doi.org/10.1093/oao/9781884446054.013.2000000028.

Recebido em 31/01/2018 - Aprovado em 02/04/2019

Como citar :

LIMA, P. E. F. (2019) A queda do céu: representação e mímesis em uma "arte índia". OuvirOUver, 15(1), 126-141. https://doi.org/10.14393/OUV24-v15n1a2019-9

(c) (7) (8) A revista ouvirOUver está licenciada com uma Licença Creative

Commons Atribuição-NãoComercial 4.0 Internacional. 